\title{
Solar Energized Re-Boost Converter For Improved Power Quality
}

P.Abirami ${ }^{1}$, M.Pushpavalli ${ }^{2}$, P.Sivagami ${ }^{3}$, V.Geetha ${ }^{4}$, S.Mohanapriya ${ }^{5}$, S.Rakshini ${ }^{6}$ Abiramiramkumar80@gmail.com ${ }^{1}$, pushpavalli.eee@sathyabama.ac.in², , sivagamitec@gmail.com², geethasendray28@gmail.com

${ }^{1} \mathrm{AP} / \mathrm{EEE}$, Sathyabama Institute of Science and Technology, Chennai

${ }^{2} \mathrm{AP} / \mathrm{EEE}$, Sathyabama Institute of Science and Technology, Chennai

${ }^{3,4} \mathrm{AP} / \mathrm{EEE}$, Sathyabama Institute of Science and Technology, Chennai

\begin{abstract}
At present, Smart grids are growing in a wider manner as an alternative to the conventional generation systems. This paper work presents the simulation results of the PV with Inverter and PV, Battery based Re-boost converter with Inverter. This work deals with the simulation of PV energized reboost converter using conventional and FOPID controller. The comparison is done in terms of time domain parameters like settling time and steady state error.The outcomes represents the superior performance of reboost converter with inverter grid connected closed loop system.
\end{abstract}

Keywords: Reboost Converter, Fractional Order PID controller. 


\section{Introduction}

Due to the technical advancement in the field of engineering there is a rapid growth in the generation, transmission and distribution of electric power which overcomes the drawback of conventional electrical grid structure. Also, the advanced invention of semiconductor devices challenges the electrical engineers for the reliability and quality of power. Most of the advanced semiconductor devices implemented over conventional grid structure are the major cause for the issues faced in the consumption of electric power at the consumer side, which in turn is a major threat to the reliability of electric power and also lead to power quality concerns. Thus, the Smart Grid concept which includes the new technologies such as Distributed Generation, Demand side management, Energy Management System, Utilization of renewable energy resources, IOT based Communication and so on, plays a vital role in finding the solution for issues faced by the conventional electric grid.

Thus, the objective of this paper is to improve quality of power by reducing the harmonics generated in the distribution network due to nonlinear loads and semiconductor devices implemented in the power converters. Now a days most of the intelligent control techniques are invented to reduce the pollution level generated at the power system. So, the consumer can be able to utilize the uninterrupted reliable power at their premises. In this work, a reboost converter (High step up DC-DC Converter) is proposed to minimize the harmonic distortions produced at the power system energized by photovoltaic renewable source of energy. The low frequency ripple can be diminished by using this converter [1],[2],[3],[4]. Though, the simulation of open loop system is carried out for circuits, the stability analysis of the circuit is achieved by closed loop system. Here, the reboost converter is controlled by PI and FOPID controllers [5].

The PV Energized reboost converter system is explained in chapter 2. The FOPID controller block diagram is discussed in chapter 3. Chapter 4 deals with simulation output grid connected system[6]. Also, step response disturbance is applied to the closed loop system and the results are analyzed. Chapter 5 concludes the proposed work and future scope is also discussed there.

\section{PV Energized Reboost Converter}

Fig.1 represents the $\mathrm{Pv}$ energized reboost converter. In this diagram, the Reboost converter is getting supply from the Photovoltaic cell. Also, the battery stores energy from the $\mathrm{PV}$ module which in turn supplies the reboost converter.

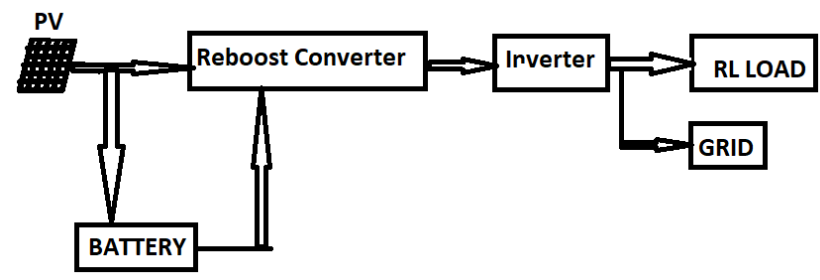

Fig 1.Diagram of PV Energized Re-boost converter 


\section{Control Techniques}

This Proposed Work Implements the FOPID controller for the closed loop system operation of the reboost converter. The three main problems we are usually facing in the simulation of power system or power electronic circuits are Stable, Unstable and Non minimum Phase systems. The proportionality, integral and derivative constants are the main parameters of a conventional PID controller. In FOPID controller $\lambda$ and $\delta$ are the control part [6]. The exchanging capacity of a FOPID controller is given as below

$\mathrm{CFOPID}_{(\mathrm{s})}=\mathrm{K}_{\mathrm{P}}+\mathrm{K}_{\mathrm{I}} / \mathrm{s} \lambda+\mathrm{K}_{\mathrm{D}} \mathrm{s} \mu$

In the above equation the integral order is represented as 'lamda' $(\lambda)$ and the derivative order is represented as ' $m u$ ' $(\mu)$, while $\mathrm{K}_{\mathrm{P}}, \mathrm{K}_{\mathrm{I}}$, and $\mathrm{K}_{\mathrm{D}}$ are constants. The control diagram of controller is given below.

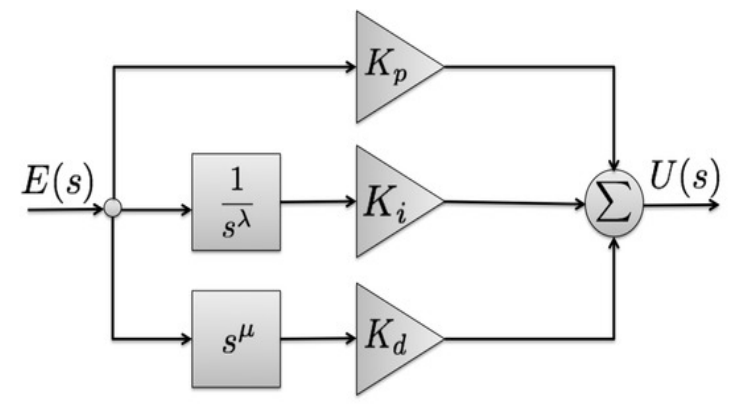

Fig 2. Control diagram of the Controller.

\section{Simulation Results and Dicussion}

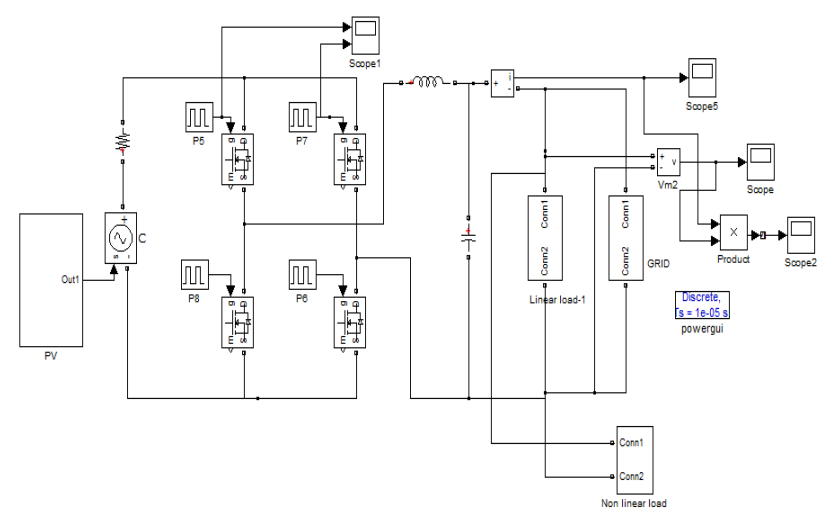

Fig 3. PV energized conventional inverter grid connected system 
Fig3 represents the conventional inverter grid connected system. The inverter is supplied by the PV source. The harmonics present in the output is minimized by connecting a LC filter between the inverter and the load. Here, various loads such as linear, non-linear and grid are considered for the simulation circuit.

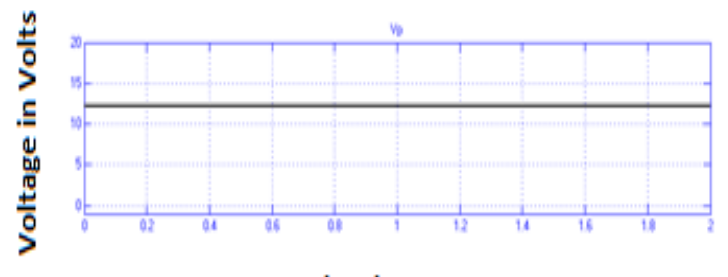

Time in Sec

Fig 4. Voltage across PV

Fig 4 represents the voltage output of PV which is given by $12.5 \mathrm{~V}$.

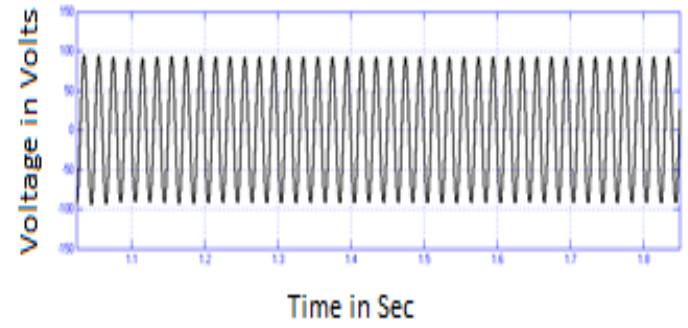

Fig 5. Voltage across RL Load

Fig 5 represents the voltage across RL load with value as90V.

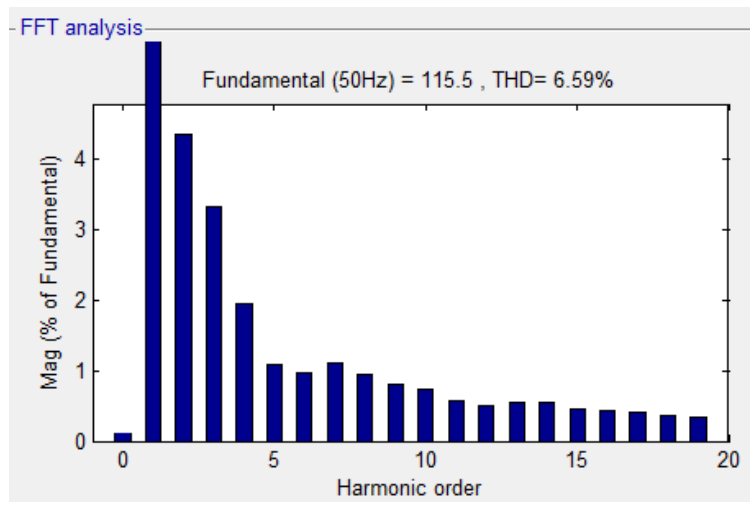

Fig 6. Harmonic analysis of output voltage 
Fig 6 represents the THD of output voltage across RL load. The fundamental frequency is $115.5 \mathrm{~Hz}$ and THD is $6.59 \%$.

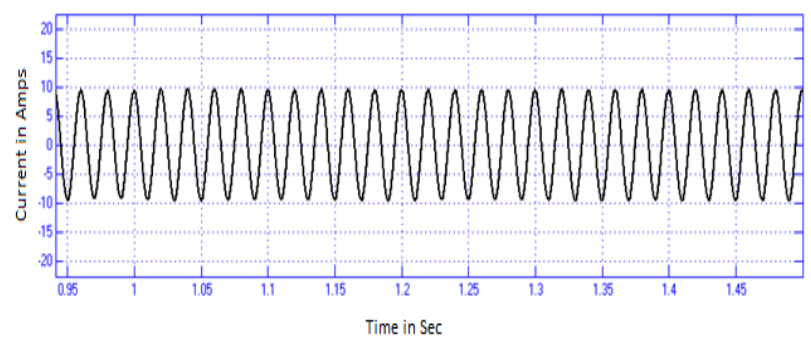

Fig 7. Current through RL Load

Fig.7 displays the current in RL load with $10 \mathrm{~A}$ as its value.

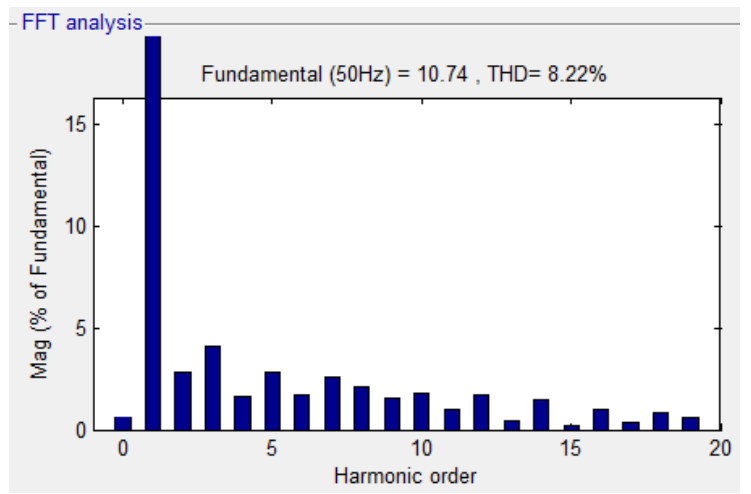

Fig 8.THD of current in RL Load

Fig. 8 gives the THD analysis of current in RL load and its THD value is $8.22 \%$.

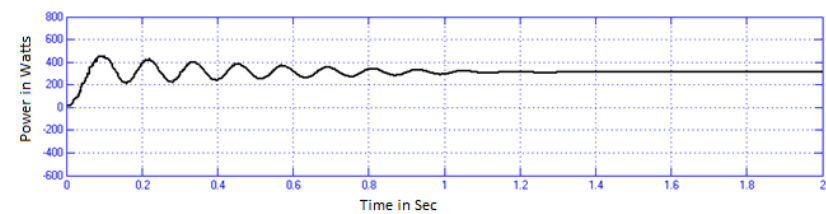

Fig 9. Output Power of Existing System

Fig 9 represents the real power of PV with inverter. The measured value is around 320 watts. But it is not a stable one.The settling time of the powersystem, the proposed reboost converter topology is adopted here.

\subsection{Circuit of Open Loop controlled Reboost Converter}




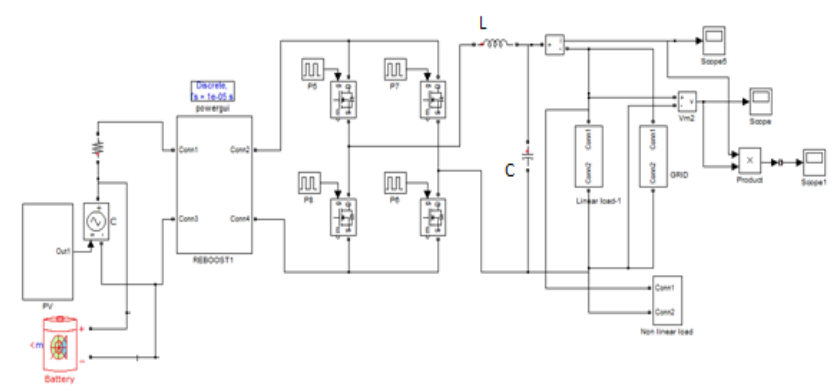

Fig 10. Re boost converter with inverter grid connected system

Fig 10 represents the circuit of open loop controlled system with inverter grid connected system.

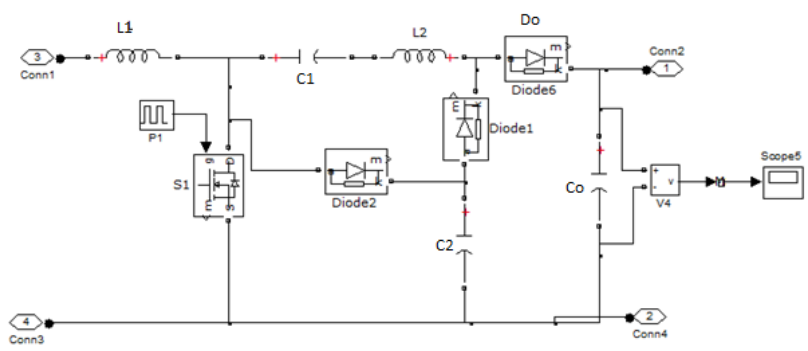

Fig 11. Circuit diagram of Reboost converter

Fig.11 represents circuit diagram of reboost converter. It consists of DC input and a transistor and also coupled inductors and a filter circuit which includes diodes,inductors and capacitors. The diode Do and Co represents the yield diode and channel capacitor of the converter [7],[8].

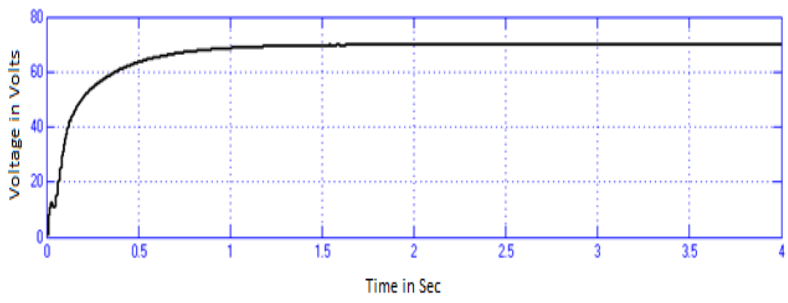

Fig 12. Voltage across Reboost Converter

Fig 12 indicates the voltage across the proposed reboost converter. It generates a voltage of $70 \mathrm{~V}$ in it. 


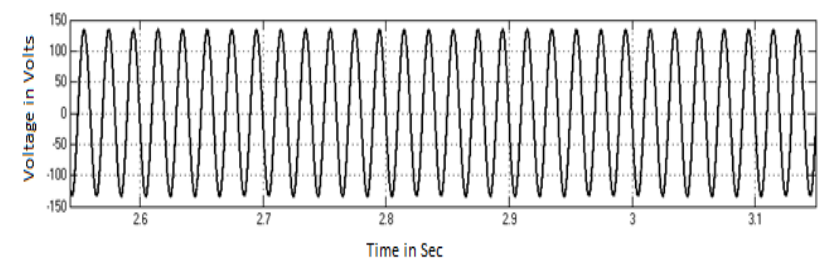

Fig 13. Voltage across RL load

Fig 13 represents the voltage across RL load in the reboost implemented circuit. Its value is nearly $135 \mathrm{~V}$.

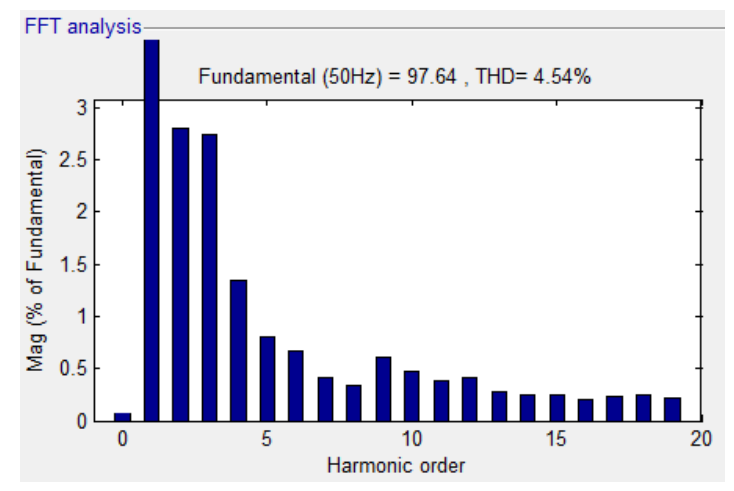

Fig 14. Harmonic analysis of output voltage

Fig 14 indicates harmonic analysis of voltage and Fig.15 represents current value observed across RL Load. The harmonic distortion measured is about $4.54 \%$ which is lesser than the

conventional

system.

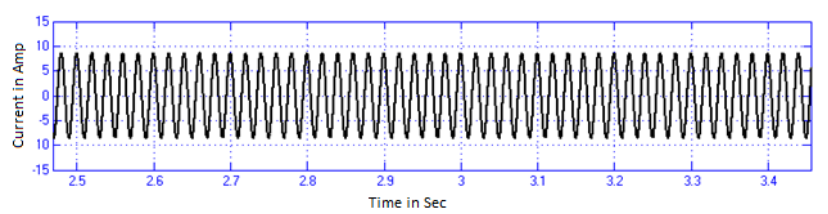

Fig 15. Output current (RL load) 


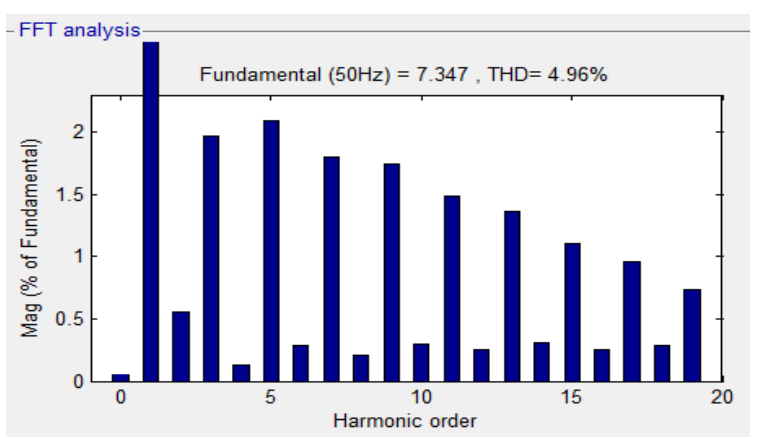

Fig 16. Harmonic Distortion of Current Waveform

Fig.16 displays the THD of current waveform and the observed value is $4.96 \%$ again it is a reduced value when compared with the conventional system[9][10].

Fig.17 Shows output power of PV energized reboost converter system. Here, the fluctuations in the output power is minimized due to the reboost converter. The power

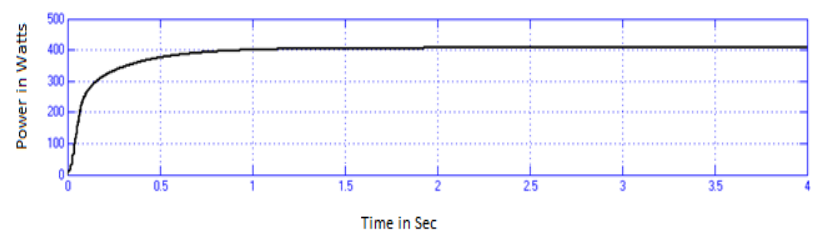

Fig 17. Output power of Proposed System

observed is 406 Watts. Also, the steady state of power is achieved at $0.8 \mathrm{sec}$ itself

Table 1 gives the comparison between $\mathrm{pv}$ with invertre and $\mathrm{pv}$ and battery based reboost converter

Table 1. Comparison between Existing and Proposed System

\begin{tabular}{|c|c|c|c|c|}
\hline Grid connected system & Vo(V) & P(W) & $\begin{array}{c}\text { Voltage THD } \\
(\%)\end{array}$ & $\begin{array}{c}\text { Current THD } \\
(\%)\end{array}$ \\
\hline PV with Inverter & $90 \mathrm{~V}$ & $320 \mathrm{~W}$ & $\mathbf{6 . 5 9}$ & $\mathbf{8 . 2 2}$ \\
\hline $\begin{array}{c}\text { PV \& Battery based } \\
\text { Re boost converter with } \\
\text { Inverter }\end{array}$ & $135 \mathrm{~V}$ & $406 \mathrm{~W}$ & 4.54 & 4.96 \\
\hline
\end{tabular}

\subsection{Circuit of PI Controlled Reboost Converter}

Fig.18 represents the simulation circuit of closed loop controlled reboost converter. The PI controller is implemented further to reduce the fluctuations in the output parameters and the ouput voltage to mitigate harmonics level. 


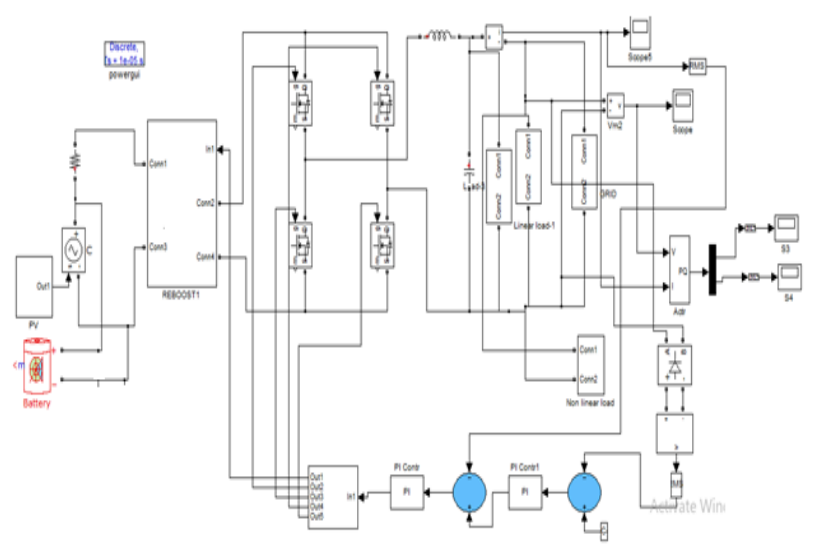

Fig 18. Circuit of PI controlled reboost converter

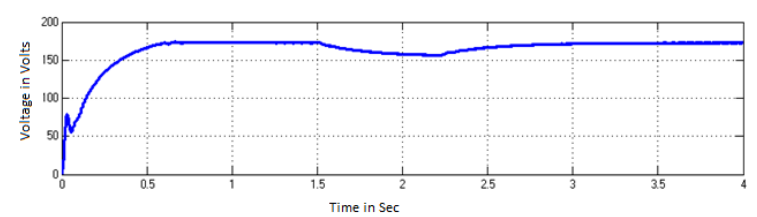

Fig 19. Voltage across PI controlled reboost converter

Fig 19 represents the voltage across PI controlled reboost converter with a step response given as disturbance to the simulation circuit at $2 \mathrm{sec}$. The voltage measured is $170 \mathrm{~V}$.

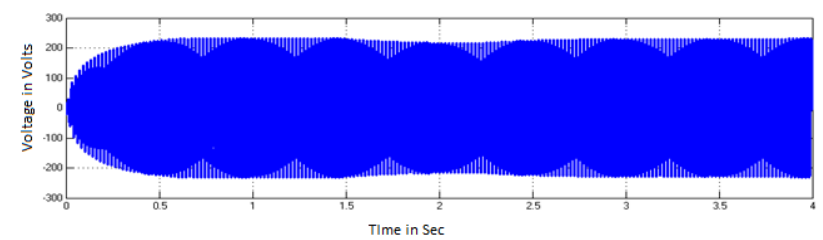

Fig 20. Voltage across RL load of PI controlled system

Fig 20 represents the output volatge of RL load of PI controlled reboost converter and it is observed as $150 \mathrm{~V}$. 


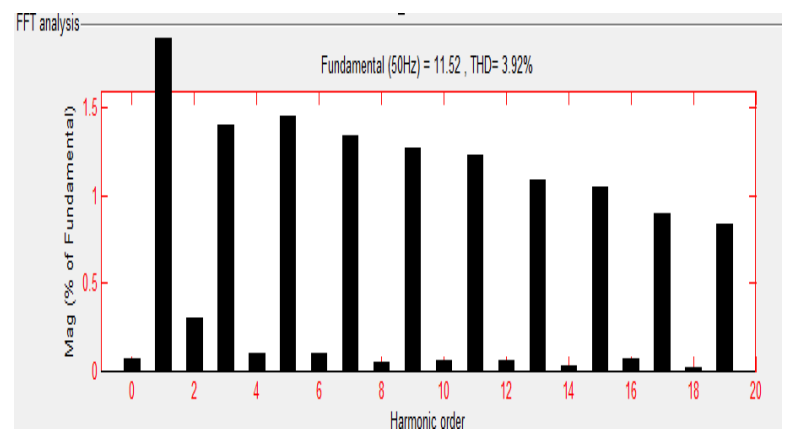

Fig 21. Distortion Level of Output voltage

Fig.21 represents THD of voltage across RL load with closed loop PI controller. The harmonic distortion measured is about $3.60 \%$.

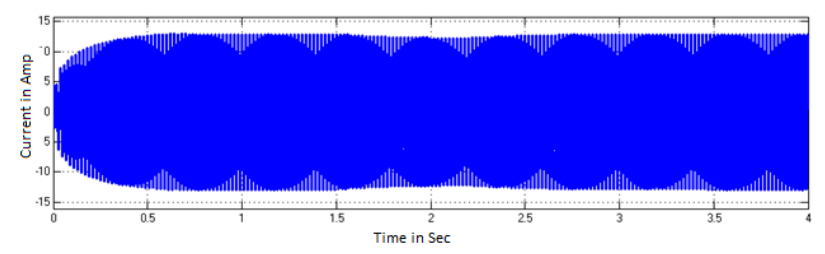

Fig 22. Current through RL load of PI controlled system

Fig 22 represents the current flowing through RL load in the closed loop system. Around 12.5A current flows through the load.

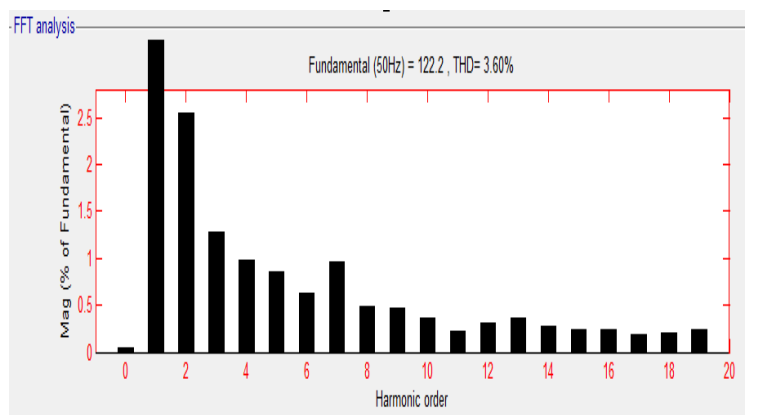

Fig 23. THD of output current

Fig 23 indicates THD analysis of current through RL load in the PI controlled reboost converter system. The harmonic distortion level has been noticed as $3.92 \%$. The fundamental frequency value is 11.52 . 


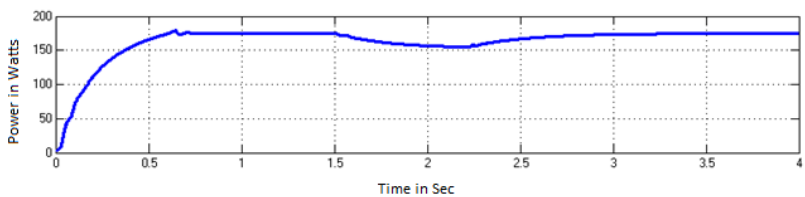

Fig 24. Real Power of reboost with PI control

Fig.24 gives the active power of reboost with PI controller. Its value is given as $175 \mathrm{~W}$.

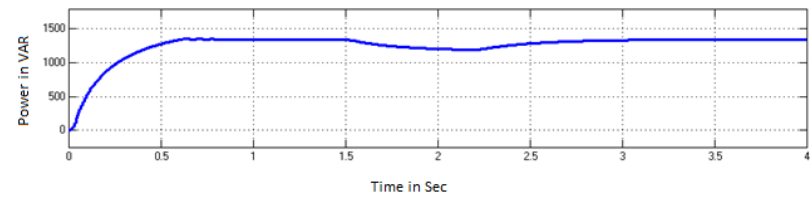

Fig 25. Reactive power of converter

Fig.25 represents the reactive power of reboost converter. The value of the power is measured as 1400 VAR.

\subsection{Circuit of FOPID Controlled Reboost Converter}

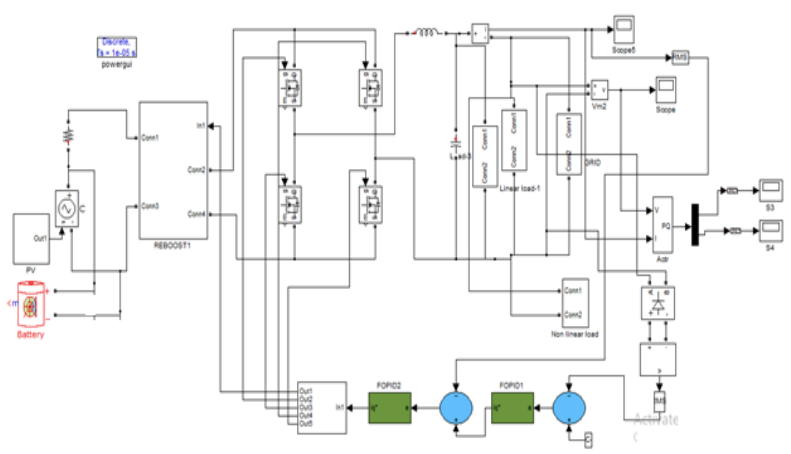

Fig 26. Circuit of FOPIDcontrolled Re boost converter

Fig 26 represents the simulation circuit of FOPID controlled PV Re boost converter with inverter grid connected closed loop system.

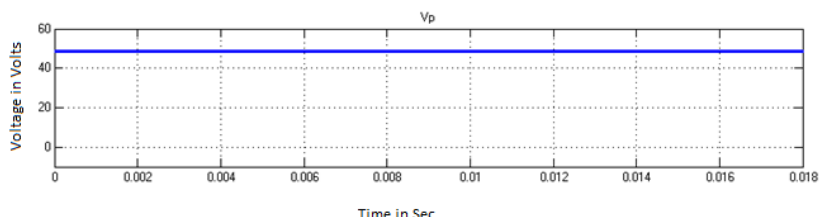

Fig 27.Voltage across PV for FOPID controlled system 
Fig 27 gives the Voltage across PV of closed loop FOPID controlled Re boost converterand its value is 50 Volts.

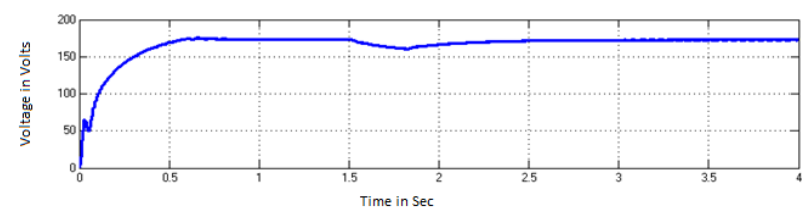

Fig 28. Voltage across FOPID controlled Re boost converter

Fig 28 shows the output voltage across FOPID controlled Re boost converterand its value is measured as 175 Volts.

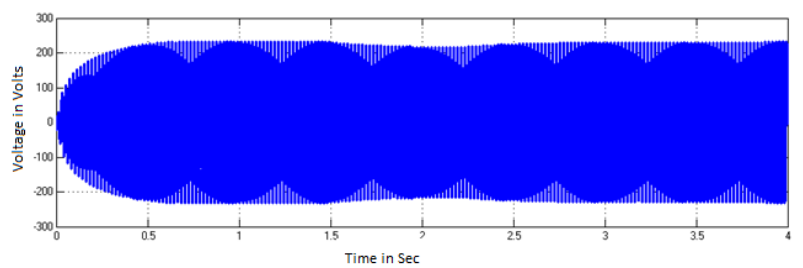

Fig 29. Voltage across RL load of FOPID controlled System

Fig 29 represents the Voltage across RL load of closed loop FOPID controlled PV Re boost converter and its value is given as 240 Volts.

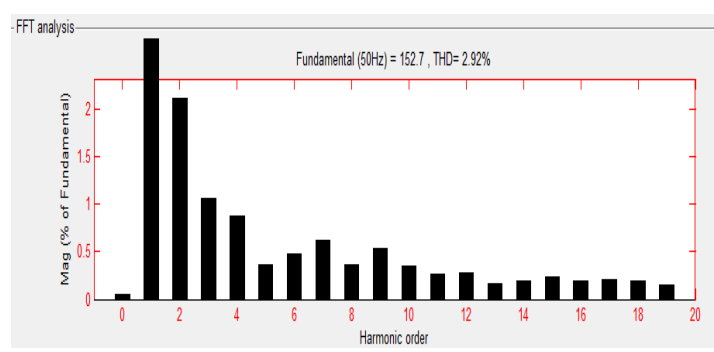

Fig 30. THD of output voltage

Fig 30 gives us the information about harmonic distortion level obtained in the voltage across the RL load of FOPID controlled system. The harmonic distortion observed is $2.92 \%$. 


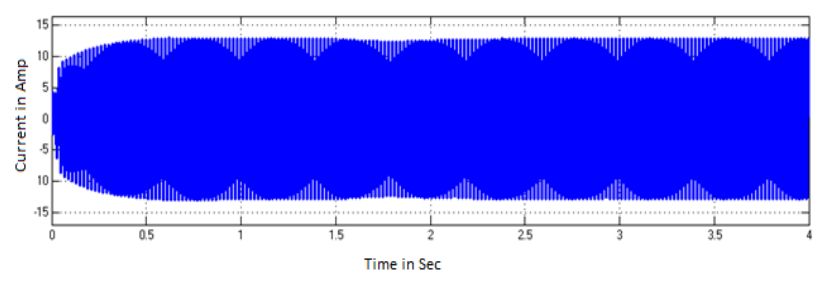

Fig31. Current through RL load of FOPID controlled system

Fig 31 indicates the amount of current flowing through RL load of closed loop FOPID controlled PV Re boost converter and its value is $12.5 \mathrm{Amp}$.

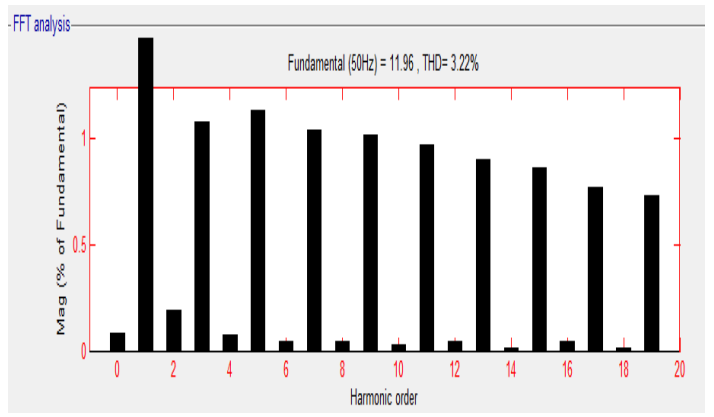

Fig 32. THD of output current

Fig 32 represents the THD of Current through RL load of FOPID controlled system. The total harmonic distortion level is measured as $3.22 \%$.

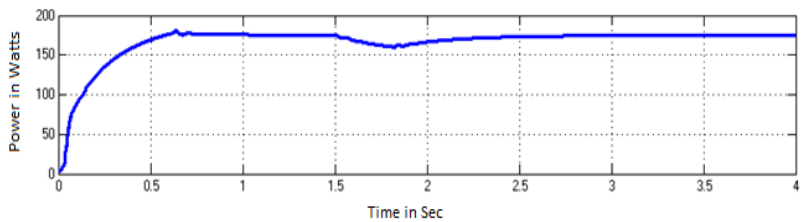

Fig 33. Active power of converter with FOPID

Fig.33 indicates the Real power of closed loop FOPID controlled PV Re-boost converter and its value is $175 \mathrm{~W}$.

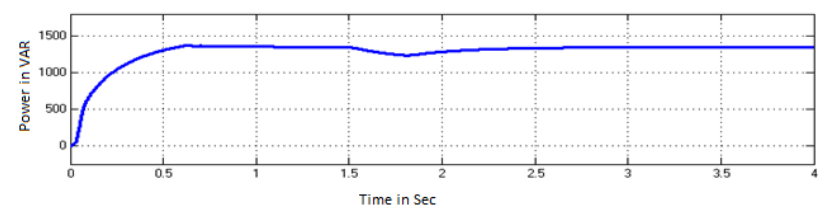

Fig 34. Reactive power of FOPID controlled system

Fig.34 represents reactive power withclosed loop FOPID controlled PV Re boost converter and its value is $1450 \mathrm{VAR}$. 
Table 2. Comparison of controllers

\begin{tabular}{|l|l|l|l|l|}
\hline Controller & $\mathrm{T}_{\mathrm{r}}$ & $\mathrm{T}_{\mathrm{s}}$ & $\mathrm{T}_{\mathrm{p}}$ & $\mathrm{E}_{\mathrm{ss}}$ \\
\hline PI & 1.64 & 2.67 & 2.21 & 3.3 \\
\hline FOPID & 1.57 & 2.04 & 1.82 & 2.4 \\
\hline
\end{tabular}

Table 2 gives the detailed comparison between the time domain specification for PI and FOPID controllers. The time domain specifications considered here are rise time, settling time, peak time and steady state error. From table it is clearly understood that the FOPID controlled reboost converter is performing better than the PI controlled reboost converter.

\section{CONCLUSION}

The PI and FOPID controllers are utilized to verify the simulation of closed loop reboost converter. From the simulated results the performance of reboost converter is analyzed with time domain parameters and the results are tabulated as in table no.2. The analysis concludes that the reboost converter with FOPID controller is performing better than the open loop and PI controlled Closed loop system of PV energized reboost converter. Thus, from the simulation results and FFT analysis of output waveforms it is clear that the harmonic distortions in the distribution network is reduced by using the proposed converter which enhances power quality. Further the proposed work can be improved by using any one of the intelligent control techniques and renewable sources can be integrated for energizing proposed converter.

\section{References}

[1] Shobana, S., Tamil Selvi,K., Abirami, P., Pushpavalli, M., Sivagami, P, "Implementation of voltage stability system in distribution network by using D-STATCOM" International Journal of Recent Technology and Engineering, ISSN: 2277-3878, Volume-8, Issue-2S11, September 2019.

[2] Christopher Hutchens, Wensong Yu, Jih-Sheng Lai Virginia, USA "Modeling and Control of Charge-Pumped Reboost Converter for PV applications" Virginia Polytechnic Institute , 978 - 1 $4244-7463-9 / 10$ IEEE 2010.

[3] Sivagami, P., Jothiswaroopan, N.M., "IOT based statistical performance improvement technique on the power output of photovoltaic system", Journal of Ambient Intelligence and Humanized Computing, April 2020.

[4] Subhransu Padhee ORCID Icon,Umesh Chandra Pati \&Kamalakanta Mahapatra "Overview of High-Step-Up DC-DC Converters for Renewable Energy Sources" taylor and francis.volume 35 2018 issue-1.

[5] P. Bhaskara Prasad, M. Padma Lalitha, B. Sarvesh, "Fractional Order PID Controlled Cascaded Reboost Seven Level Inverter Fed Induction Motor System with Enhanced Response" International Journal of Power Electronics and Drive System (IJPEDS) Vol. 9, No. 4, December 2018, pp. 1784 1791 ISSN: 2088-8694, DOI: 10.11591/ijpeds.v9.i4.pp1784-1791.

[6] Pushpavalli, M., Jothi Swaroopan, N.M., "KY converter with fuzzy logic controller for hybrid renewable photovoltaic/wind power system" Transactions on Emerging Telecommunications Technologies, June 2020. 
[7] Vanitha Soman and Sudhakar S Mande, "Design of a Two-Stage Folded Cascode Amplifier Using SCL $180 \mathrm{~nm}$ CMOS Technology”, International Conference on Communication, Computing and Electronics Systems Series, (pp. 423-430), Springer, 2020.

[8] Abirami, P., George, M.L, "Implementation of NN controlled DVR for enhancing the power quality by mitigating harmonics" International Journal of Power Electronics and Drive Systems, Vol.9, no.2, 2018.

[9] W. Li, Y. Zhao, J. Wu, and X. He, "Interleaved high step-up converter with winding-cross-coupled inductors and voltage multiplier cells," IEEE Trans. Power Electron., vol. 27, no. 1, pp. 133-143, Jan. 2012.

[10] Illavarason, P., Renjit, J.A. and Kumar, P.M., 2019. Medical diagnosis of cerebral palsy rehabilitation using eye images in machine learning techniques. Journal of medical systems, 43(8), p.278. 